\title{
Impaired Upper Esophageal Sphincter Reflexes in Patients with Supra-Esophageal Reflux Disease
}

\author{
Arash Babaei, Mukund Venu, Sohrab Rahimi Naini, Jason Gonzaga, Ivan Lang, Benson \\ Massey, Sudarshan Jadcherla, and Reza Shaker \\ Division of Gastroenterology and Hepatology, Medical College of Wisconsin, Milwaukee, WI, USA
}

\begin{abstract}
Background \& Aims-Normal responses of the upper esophageal sphincter (UES) and esophageal body to liquid reflux events prevent esophagopharyngeal reflux and its complications, but abnormal responses have not been characterized. We investigated whether patients with supraesophageal reflux disease (SERD) have impaired UES and esophageal body responses to simulated reflux events.
\end{abstract}

Methods-We performed a prospective study of 25 patients with SERD (19-82 y old, 13 female) and complaints of regurgitation and supra-esophageal manifestations of reflux. We also included 10 patients with gastroesophageal reflux disease (GERD; 32-60 y old, 7 female) without troublesome regurgitation and supra-esophageal symptoms and 24 healthy asymptomatic individuals (controls; 19-49 y old, 13 female). UES and esophageal body pressure responses, along with luminal distribution of infusate during esophageal rapid and slow infusion of air or liquid, were monitored by concurrent high-resolution manometry and intraluminal impedance.

Results-A significantly smaller proportion of patients with SERD had UES contractile reflexes in response to slow esophageal infusion of acid than controls or patients with GERD. Only patients with SERD had abnormal UES relaxation responses to rapid distension with saline. Diminished esophageal peristaltic contractions resulted in esophageal stasis in patients with GERD or SERD.

Conclusions-Patients with SERD and complaints of regurgitation have impaired UES and esophageal responses to simulated liquid reflux events. These patterns could predispose them to esophagopharyngeal reflux.

Corresponding Author: Reza Shaker, MD, 9200 West Wisconsin Avenue Milwaukee, WI 53226, Phone: 414.955.6840, Fax: 414.955.6215,rshaker@mcw.edu.

Dr. Babaei had a major role in study concept, data acquisition, data analysis, interpretation of data, statistical analysis, drafting of the manuscript, and critical revision of the manuscript for important intellectual content. Dr. Venu, Dr. Rahimi Naini and Dr. Gonzaga had a major role in study concept and data acquisition. Dr. Massey and Dr. Lang contributed to the interpretation of data, drafting and critical revision of the manuscript. Dr. Jadcherla had a major role in concept development and revision of the manuscript for important intellectual content. Dr. Shaker had a major role in study concept and design, acquisition and interpretation of the data, funding and supervision of the project, and critical revision of the manuscript.

Publisher's Disclaimer: This is a PDF file of an unedited manuscript that has been accepted for publication. As a service to our customers we are providing this early version of the manuscript. The manuscript will undergo copyediting, typesetting, and review of the resulting proof before it is published in its final citable form. Please note that during the production process errors may be discovered which could affect the content, and all legal disclaimers that apply to the journal pertain.

The authors have no conflict of interest to disclose. 


\section{Keywords}

extra-esophageal reflux; EUCR; EURR; striated esophagus; cervical; laryngopharyngeal reflux

\section{INTRODUCTION}

Reflux of gastric content into the esophagus triggers a number of reflexes involving the upper esophageal sphincter (UES) $)^{1,2}$, and esophageal body ${ }^{2,3}$. These reflexes serve to protect the pharynx and upper airways from entry of the noxious refluxate into the pharynx, esophagopharyngeal reflux (EPR), and transport the refluxate back into stomach ${ }^{4}$. Nearly half of patients with gastroesophageal reflux disease (GERD) complain of supra-esophageal symptoms $^{5}$, and EPR has been implicated in pathogenesis of supra-esophageal symptoms $s^{6,7}$.

Creamer and Schlegel first described the purposeful pattern of UES contraction, peristaltic esophageal contraction and lower esophageal sphincter (LES) relaxation in response to esophageal liquid/balloon distention ${ }^{1}$. They proposed that the ensemble of esophageal reflexes transport esophageal content into the stomach and protect the pharynx and upper airways. However, the role of the UES and esophageal reflexes in the pathophysiology of reflux associated supra-esophageal disorders remained controversial. Some studies suggested that GERD patients who complain of regurgitation do not show UES response to esophageal saline or acid infusion ${ }^{8}$; whereas others reported a preserved UES contractile response in GERD patients similar to healthy controls ${ }^{9}$. On the other hand, some investigators doubted the existence of UES contractile response both in normal subjects and reflux patients ${ }^{10,11}$.

Studies to date have not definitively shown whether abnormalities in the protective esophago-UES reflexes exist, or how such potential abnormalities may result in EPR. The reasons for inability of prior studies to address this issue may include subject selection (since abnormities may have only been present in a subset of GERD patients), and differences in study technique and recording equipment ${ }^{9,12}$. Recent studies of both naturally occurring and simulated reflux events in normal subjects have shown that supine posture and slow rate of esophageal pressure rise during esophageal liquid distention significantly increase the frequency of elicitation of esophago-UES contraction reflex (EUCR), and inversely decrease the frequency of elicitation of esophago-UES relaxation reflex $(\mathrm{EURR})^{2}, 13$. The recent development of high-resolution manometry with concurrent intraluminal impedance recording has lead to enhanced spatial pressure monitoring and objective verification of the luminal distribution of esophageal contents. Using this modality, along with a well-defined stimulation technique could resolve the current paradox in the literature. The aim of the present study was to challenge UES and esophageal reflexes in a controlled simulated reflux model in GERD patients with and without supraesophageal complaint to determine if specific alterations in these reflexes exist, which could predispose to the occurrence of EPR. 


\section{METHODS}

Since spontaneous EPR events are relatively infrequent and their composition and occurrence is unpredictable, we adopted the esophageal infusion model with controlled timing and composition of infusate to simulate reflux events in subjects ${ }^{2}$. Studies were conducted in supine position for liquid infusion during which the airway is more vulnerable, and physiologic demand for protective esophago-UES reflexes is greater. The first phase of the current study was designed to mimic rapid reflux events by rapid bolus injection, and the second phase of study was designed to simulate prolonged reflux episodes by slow acid infusion.

\section{Study Participants}

We studied three distinct groups of subjects. Study participants were classified based on their clinical diagnosis and symptomatic profile. 1) Twenty-five (20-82 years, 13 Female) patients who had an established clinical diagnosis ( $>2$ years) of GERD. All patients were followed by their primary gastroenterologist in a tertiary care referral center and were on stable doses of acid suppressive therapy that adequately controlled their typical heartburn. Despite ongoing therapy, all patients complained of persistent troublesome regurgitation along with at least one supra-esophageal manifestation (chronic cough, burning throat, or hoarseness). Hereafter, we call this group supra-esophageal reflux disease (SERD). 2) Ten patients (ages 32-60, 7 female) having a clinical diagnosis of GERD, with a dominant symptom of heartburn that responded to medical therapy. This group did not have troublesome regurgitation and/or supra-esophageal symptoms. 3) Twenty-four (19-49 years, 13 Female) healthy controls without reflux symptoms. None of the study participants had a history of prior esophageal or gastric surgery. The institutional review board of the Medical College of Wisconsin approved the study protocol and all volunteers signed an informed written consent.

\section{Study Protocol}

Following 6 hours of fasting, a catheter assembly consisting of a combined high-resolution manometry/impedance catheter, and an infusion tube $(2.4 \mathrm{~mm})$ was inserted into the esophagus through the same nostril following topical anesthetic application. The highresolution manometry/impedance catheter contained 36 circumferential solid-state pressure sensors spaced $1 \mathrm{~cm}$ apart and 19 interspersed impedance rings spaced $2 \mathrm{~cm}$ apart (Given Imaging, Los Angeles, CA). The infusion port was placed in the distal third of esophagus and the site was confirmed by impedance signature of air injection in the upright position. Air injections were performed in semi-upright position when belching is physiologically more common ${ }^{2}$. Then, subjects were placed in a recumbent position for the remainder of the study protocol, and each infusion was performed when the UES, LES and esophageal pressures were stable at baseline ${ }^{2}$. Volunteers were instructed not to suppress their belch or swallow response. UES pressure was measured by e-sleeve ${ }^{\mathrm{TM}}$ function of the Manoview ${ }^{\mathrm{TM}}$ software (Given Imaging, Los Angeles, CA). Study protocol was generally conducted in two sessions: 
Session I consisted of rapid bolus injection of air and saline in 18 healthy controls, 8 GERD and 19 SERD patients. We injected 10, 20,30 and $50 \mathrm{ml}$ of air $(\sim 100 \mathrm{ml} / \mathrm{s})$ and 10,20 and $30 \mathrm{ml}$ of saline $(\sim 10 \mathrm{ml} / \mathrm{s})$ for a total of three repetitions as described previously ${ }^{2}$. Rather than using an arbitrary time window after infusion, we analyzed 420 trials of supra-threshold (>10 ml) rapid air and saline injections in 30 healthy controls studied in our laboratory (previous and current study) to determine the ideal time window for UES and esophageal pressure analysis. In healthy controls, UES response to air and saline injection was observed in $0.4 \pm 0.7$ and $2.1 \pm 1.3$ seconds (mean $(\mathrm{M}) \pm$ standard deviation (SD)) respectively. Considering a conservative margin of three SD from mean of healthy control subjects, the UES analysis window of 2.5 and 6 seconds (for air and saline respectively) after rapid injection was established. UES response to rapid injection was categorized as formerly described $^{2}$ : (1) Contraction, if UES pressure exceeded the baseline pressure by greater than $10 \mathrm{mmHg}$; (2) Relaxation, if UES pressure dropped more than $10 \mathrm{mmHg}$ below the baseline pressure or equalized to cervical esophageal pressure; (3) Swallow if manometric signature of swallow was observed; and (4) No response, if the pressure changes were less than 10 $\mathrm{mmHg}$ threshold or outside the analysis time window. Esophageal contractile response to air and saline injection was observed in $2 \pm 1.9$ and $4.4 \pm 3.6$ seconds $(\mathrm{M} \pm \mathrm{SD})$ respectively. Therefore, esophageal analysis window was determined 7.7 and 15.2 seconds for air and saline respectively. Esophageal response was categorized according to previous descriptions $^{2}$ : (1) Primary peristalsis associated with swallow; (2) Secondary peristalsis; (3) Non-peristaltic contraction; and (4) No response, if the esophageal pressure activity was less than $20 \mathrm{mmHg}$ or $5 \mathrm{~cm}$ in length or outside the analysis time window. Subsequently, clearance of the infusate from the esophagus was monitored using esophageal intraluminal impedance for 60 seconds.

Session II consisted of slow infusion of acidic liquid in 12 healthy controls, 9 GERD and 15 SERD patients. Nine SERD patients, seven GERD patients and six healthy controls participated in both study sessions. We injected $60 \mathrm{ml}$ of acid slowly using a $60 \mathrm{ml}$ syringe over one minute $(1 \mathrm{ml} / \mathrm{s})$, for a total of three repetitions. Two patients reported heartburn and mild nausea after the final infusion trial but were able to tolerate and finish the study protocol. We used a buffered acid solution with a stable $\mathrm{pH}$ of 1.4 (MD Custom Pharmacy, Brookfield, WI). Similar to session I, post-infusion analysis time window for UES and esophageal contractile responses were determined 8.4 and 23.3 seconds respectively. The rate and type of esophageal body contractions during the 60 -second ongoing period of acid infusion was measured. Subsequently clearance of the infusate from the esophagus using the intraluminal impedance was monitored for 180 seconds after termination of acid infusion.

\section{Statistical Analysis}

We analyzed the frequency of elicitation of each type of response, considering the predominant UES or esophageal response (mode among three trials) across tested volumes, as well as all volumes similar to previous reports ${ }^{2}$. The frequency of the UES and esophageal response between groups was compared using Fisher's exact test. The amplitude, temporal and rate characteristics of the pressure responses were compared using analysis of variance, followed by unpaired two-tailed t-test when appropriate. 


\section{RESULTS}

Representative examples of concurrent high-resolution manometry and intraluminal impedance color-contour plots during rapid saline, slow acid and rapid air infusions are shown in Figure 1, 3, 6 respectively. X-axis of each panel represents time and y-axis corresponds to 36 pressure sensors extending from pharynx to the esophagus. Superimposed purple color-contour plot (when shown) represents intraluminal impedance and indicates luminal distribution of saline/acid after injection. UES sleeve pressure is demonstrated as an orange tracing overlay in some figures for clarifying EUCR. In some panels, UES and hypopharyngeal intraluminal impedance tracings are superimposed to better demonstrate infusate movement inside the lumen.

\section{I) Rapid Saline Injection}

The predominant UES response following the rapid saline injection was EUCR in healthy controls and GERD patients (Figure 1). SERD subjects were less likely to exhibit EUCR as compared to GERD and healthy controls ( $42 \%$ versus $88 \%$ and $83 \%$ respectively, Figure $2 \mathrm{~A})$. The esophageal body response to rapid saline injection was predominantly peristaltic in healthy controls (94\%). Both SERD and GERD patients differed significantly from healthy volunteers by having less frequent peristaltic contractions (50\% and 58\%, Figure $2 \mathrm{~B}$ ). When EUCR occurred in response to rapid saline injection, the amplitude of contraction was similar in all groups $(62 \pm 25 \mathrm{mmHg})$. The onset of esophageal peristaltic or non-peristaltic motor response was significantly delayed in GERD and SERD patients compared to healthy subjects (Figure 2C), while the onset of UES response was not significantly different across groups. Esophageal contractile response to rapid saline injection occurred after the onset of UES response. Furthermore, in both SERD and GERD groups, absence of a peristaltic esophageal motor response resulted in significantly delayed esophageal clearance (Figure 2D).

The UES relaxation response in the time window of analysis after rapid saline injection was only seen in SERD patients (23/171 trials in 5/19 patients), and the average residual UES relaxation pressure during these episodes was $16 \pm 12 \mathrm{mmHg}$. Some of the episodes of UES relaxation were associated with impedance evidence of retrograde trans-UES liquid movement (EPR) as shown in Figure 1D-F.

\section{II) Slow Acid Infusion}

In healthy controls and GERD patients similarly, the UES tone increased significantly (EUCR) and remained elevated during continuous slow distal esophageal infusion (Figure 3A-D). Compared to healthy controls and GERD patients, SERD patients were significantly less likely to exhibit EUCR ( $92 \%$ and $89 \%$ versus $20 \%$ respectively). Indeed 53\% of SERD patients did not mount any UES response, while all healthy controls displayed UES response in the time window of analysis (Figure 4A). SERD patients demonstrated a significantly lower frequency of peristaltic response (47\%) compared to healthy controls $(100 \%)$; the response in GERD patients (78\%) was intermediate between these two groups (Figure 4B). Non-peristaltic esophageal contractions were not only more common in both GERD and SERD patients (33\%), but also exhibited delayed onset (Figure 4C). In addition to the lower 
frequency and delayed protective reflexes in SERD patients, UES and esophageal motor responses were often discordant. That is, either esophageal peristalsis was not complemented by a robust EUCR (Figure 3E), or EUCR was not accompanied by clearing peristaltic contractions (Figure 3F).

Over the entire period of the slow acid infusion trials (three minutes), the rate of overall esophageal contractile response was not statistically different between groups (Figure 4D). However, in both GERD and SERD groups esophageal motor response was non-peristaltic. Only 1 out of 12 healthy controls showed non-peristaltic contractions during slow acid infusion, while 5/9 GERD and 13/15 SERD patients displayed significantly higher nonperistaltic contractions (Figure 4D). Overall the difference in esophageal motor response pattern was associated with a significantly delayed esophageal clearance in GERD and SERD patients (Figure 4E).

During this study, we observed a novel pattern of esophageal peristaltic waves limited to the striated-muscle esophagus (Figure 5A-B). These contractions were not preceded by pharyngeal contractile activity and displayed similar topographic length, duration, and amplitude to adjacent swallow-related striated contractions. These isolated striated peristaltic contractions were not accompanied by distal esophageal smooth-muscle segment contractile activity. This striated peristaltic activity was seen significantly more frequently in healthy controls compared to SERD subjects (Figure $5 \mathrm{C}-\mathrm{D}$ ). The rate of striated peristalsis in GERD patients was in between the two groups but was not significantly different from either (Figure 4D).

\section{III) Rapid Air Injection}

The predominant UES response to distal esophageal rapid air injection was EURR in healthy controls, GERD and SERD patients. The esophageal body commonly showed early distal non-peristaltic contraction (Figure 6A), peristaltic contraction (Figure 6B) or no discernable contractile activity (Figure 6F). SERD patients were significantly less likely to show peristaltic contraction compared to healthy controls and GERD patients $(p<0.05$, Figure 7B). Esophageal non-peristaltic contractile response to rapid air injection was always after EURR ( $p<0.01$ ), and peristaltic contraction was significantly delayed compared to nonperistaltic contraction across groups (Figure 7C). UES and esophageal response delay, magnitude, and duration of the response did not differ between groups ( $p>0.3)$. The observed non-peristaltic contractions as shown in $6 \mathrm{~A}$ and $6 \mathrm{C}-\mathrm{E}$ were not consistent with pan-esophageal isobaric pressure waves; rapid air infusion universally was completed by 0.5 $\mathrm{s}$, while onset of esophageal contraction was greater than one second after onset of air injection (Figure 7C). Therefore, the recorded esophageal non-peristaltic contraction was not simply due to air-induced esophageal pressurization.

\section{DISCUSSION}

The present study documented impaired UES and esophageal responses to simulated reflux events in SERD patients. These include: 1) significant deterioration of EUCR reflex in response to intraesophageal slow acid and rapid saline infusions in SERD patients compared to both healthy controls and GERD patients without supraesophageal symptoms; 2) 
occasional relaxation of UES to rapid saline injection in SERD patients that was never seen in healthy controls and GERD patients; 3) non-peristaltic esophageal contractions in response to both rapid and slow liquid infusion in both GERD and SERD patients associated with esophageal stasis; 4) occasional concurrent occurrence of non-peristaltic esophageal contraction along with relaxation of UES during esophageal stasis associated with impedance evidence of EPR; and 5) distinctive peristaltic motor activity isolated to striated muscle segment of esophagus in healthy controls that was rarely observed in SERD patients. These findings suggest that the observed unique impairment of UES reflexive responses along with impaired esophageal body response to fluid infusion in SERD patients can be mechanistically involved in the development of EPR.

The underlying mechanism for the abnormalities identified in this study are not completely understood. EUCR and esophageal contractile response are both mediated through esophageal slowly adapting mechanoreceptors believed to reside within the muscularis propria ${ }^{14}$. Animal studies have shown that EUCR and proximal esophageal contractile response above an esophageal distending balloon are vagally mediated and cholinergically dependent ${ }^{14,15}$, while phasic esophageal contractile response at the site of balloon distention and distally is preserved even after vagotomy and is not sensitive to cholinergic blockade ${ }^{15}, 16$. Based on the observation that the UES was able to mount a response more frequently when greater sensory stimulus of rapid saline injection (compared to slow) was applied; and based on presence of delayed but normal amplitude UES and esophageal contractile response in patients we speculate that the observed differences between healthy controls, GERD and SERD patients could be in part due to graded dysfunction of the afferent arm of the esophageal and UES reflexes.

Earlier investigations have attempted to differentiate between patients and healthy controls by studying the UES response to saline/acid ${ }^{8}$, and air induced esophageal distention ${ }^{17}$. A previous study using acid/saline for esophageal distention reported "no significant UES pressure response" to slow infusion ( $11 \mathrm{ml} /$ minute) in GERD patients with complaint of regurgitation ${ }^{8}$. This study proposed that failure of UES contractile response and low UES baseline pressure were important factors in the pathogenesis of pharyngeal reflux ${ }^{8}$. However, the limitations of pressure recording technique including use of a single side-hole in a water perfused manometry system to measure UES pressure, could have resulted in under-estimation of EUCR and unreliable UES pressure measurements. Using air to distend the esophagus, a recent study reported significantly higher UES relaxation response in laryngitis patients compared to healthy controls, suggesting a lower threshold for EURR and a hypersensitive belch response in these patients as the underlying mechanism of regurgitation ${ }^{17}$. The role of a hypersensitive air-induced belch in pathogenesis of regurgitation which involves passage of liquid from esophagus into the pharynx is not clear. As reported in current and previous studies, UES response to liquid distention is contraction which is opposite to that of air distention ${ }^{2}, 13$; Based on this crucial difference it is unlikely that reported difference in threshold to air distention can account for regurgitation which involves primarily liquid. However, it is worth noting that in the present study using multiple volumes of air injection could not differentiate GERD and SERD patient groups from healthy controls. Differences in the volume of injected air, recording technique and varying criteria of outcome measured could be responsible for this discrepancy. Profound 
UES abnormalities of SERD patients in response to slow esophageal liquid distention compared to both healthy controls and GERD patients, suggests that slow liquid distention is a more reliable stimulus in unmasking UES abnormalities than air.

"Esophageal stasis" due to dysmotility of esophageal body has been previously proposed as a risk factor for EPR. A retrospective review ${ }^{18}$ of a total of 612 videofluoroscopic swallow studies concluded that underlying esophageal dysmotility and impaired esophageal clearance was strongly associated with radiographically identified EPR (20\% of patients undergoing these studies). Another study has shown that GERD patients with concomitant otolaryngologic and respiratory symptoms (chronic cough, asthma and laryngitis) displayed ineffective esophageal motility associated with delayed esophageal acid clearance more frequently than GERD patients without such symptoms ${ }^{19}$. In addition, a recent study in chronic cough patients showed that those with positive symptom association probability had a higher rate of ineffective esophageal body contraction ${ }^{20}$. The findings of the above mentioned studies suggest that coexistence of dysmotility-related esophageal stasis in GERD patients may place these patients at higher risk for reflux induced respiratory symptoms. However, studies exploring the effect of reflux on esophageal motor function ${ }^{21-26}$, are generally limited to the response of distal smooth muscle esophagus. Nonperistaltic distal esophageal motor activity observed in the current study accompanied by significantly impaired esophageal clearance in GERD and SERD patients is consistent with these previous reports. Moreover, our data signify the crucial role of the striated muscle portion of the esophagus as an integral airway protective element along with the UES. The present study indicates that esophageal motor impairment in SERD patients extends into the striated segment of the esophagus, as evidenced by the diminished esophageal striated motor activity. Abnormal esophageal striated muscle response to refluxate may be even more important for airway protection than that of distal smooth muscle esophagus, since failed cervical clearance allows potential noxious material to reach the UES and cross into the pharynx and upper airways during UES hypotensive or swallow-induced relaxation episodes. Isolated esophageal striated muscle peristalsis was not only the predominant pattern of esophageal motor response in three healthy controls and one GERD patient, but also frequently preceded UES relaxation associated with swallowing in healthy controls. This seems to function to keep the cervical esophagus clear of liquid, and protect the UES from retropulsion of liquid during swallowing induced UES opening (Figure 5A-B). SERD patients, on the other hand, infrequently demonstrated peristaltic striated motor response; and as a consequence infusate reached and remained within the cervical esophageal lumen, and at times even breached the UES during swallow-related UES relaxation (Figure 5C-D). The present study may explain the mechanism of swallow-related pharyngeal reflux of esophageal infusate described in earlier limited studies ${ }^{27}$.

The exact underlying mechanism of observed striated peristaltic contractions in healthy controls, and distal non-peristaltic contractions in GERD and SERD patients awaits further investigation. Studies attempting to inhibit progression of esophageal secondary peristalsis by experimental esophageal distention induced by air injection have yielded inconsistent results. While some reported inhibition of secondary peristalsis by esophageal injection of $15 \mathrm{ml}$ of air in the proximal esophagus in $70 \%$ of injection trials ${ }^{28}$, others described only $10 \%$ interruption of secondary peristaltic waves by injection of $20 \mathrm{ml}$ of air in the middle 
esophagus ${ }^{29}$. Irrespective of the frequency of inhibition, these studies show that esophageal distention by intraesophageal injection is capable of inhibiting smooth muscle peristalsis. In the current study, esophageal striated muscle peristaltic waves started when acidic infusate reached the cervical esophagus and was repeatedly generated every 5-6 seconds till cessation of slow acid infusion. Rhythmic isolated striated segment peristaltic activity in the absence of distal esophageal smooth muscle peristalsis during slow esophageal liquid distention, may represent inhibition of smooth muscle activity resembling distal esophageal quiescence observed during sustained balloon distention in animal models ${ }^{16}$. On the other hand, delayed esophageal non-peristaltic contractions seen in GERD and SERD patients could be associated with "esophageal stasis" related distention, comparable to myogenic esophageal non-peristaltic contractions reported during sustained balloon distention ${ }^{15}, 16$.

Laryngopharyngeal reflux (LPR) and gastroesophageal reflux patient groups encompass heterogeneous populations that have made mechanistic investigation of pathophysiologic relationship between these conditions difficult. We intentionally studied a selected group of patients who demonstrate symptomatic overlap with persistent complaint of regurgitation and supra-esophageal symptoms despite acid suppressive therapy (supra-esophageal reflux disease $=$ SERD), and hypothesized that SERD patients would have a higher likelihood of demonstrating defects in protective UES responses compared to GERD patients without such symptoms. Although our findings supported that hypothesis, it is important to recognize that impaired response in this population does not occur consistently with every stimulus event. While SERD patients can mount normal protective responses to some esophageal infusion episodes, they do not do so with the uniform consistency of healthy subjects or their GERD counterparts. These findings suggest the existence of various degrees of abnormalities among SERD patients. We should acknowledge the limitations of the present study. The studied population was too small to investigate clinical features that might predict differences in severity of impairment among these patients. We did not attempt to test the UES response during rapid acid infusion due to our concern for volume regurgitation of acid in SERD patients, and future studies are needed to determine if slow infusion of saline would unmask similar abnormalities in SERD patients. We did not study spontaneous gastroesophageal reflux, because the critical uniformity of the stimuli (constituents, volume and rate of distention) in these disparate naturally occurring events cannot be ascertained. Therefore we investigated only well-defined simulated reflux events in recumbent position when airways are more vulnerable to noxious consequences of EPR. Broad clinical application of the proposed esophageal infusion paradigm needs further carefully designed studies to establish diagnostic validity, and extrapolation of the current findings to the diverse group of GERD and LPR patients awaits further investigation.

In summary, the present study identifies and characterizes the impairments of UES and esophageal reflexes in response to simulated reflux events in SERD patients. It is proposed that these impairments are mechanistically linked to esophago-pharyngeal reflux and may contribute to genesis of supra-esophageal symptoms in SERD. 


\section{Acknowledgments}

This project was supported in part by NIH Grants P01DK068051, R01DK025731, 8UL1TR000055 from the Clinical and Translational Science Award (CTSA) program of the National Center for Advancing Translational Sciences and the national center for research resources and advancing translational sciences through 8KL2TR000056 grant.

\section{Glossary of abbreviations}
UES
Upper Esophageal Sphincter
LES
Lower Esophageal Sphincter
EUCR
Esophago-UES contractile reflex
EURR
Esophago-UES relaxation reflex
EPR
Esophago-pharyngeal Reflux
GERD
Gastro-esophageal Reflux Disease
SERD
Supra-esophageal Reflux Disease

\section{References}

1. Creamer B, Schlegel J. Motor responses of the esophagus to distention. J Appl Physiol. 1957; 10:498-504. [PubMed: 13438808]

2. Babaei A, Dua K, Naini SR, et al. Response of the Upper Esophageal Sphincter to Esophageal Distension Is Affected by Posture, Velocity, Volume, and Composition of the Infusate. Gastroenterology. 2012

3. Meltzer SJ. Secondary peristalsis of the esophagus - a demonstration on a dog with a permanent esophageal fistula. Proc Soc Exper Biol \& Med. 1906; 3:35-37.

4. Shaker R, Lang IM. Reflex mediated airway protective mechanisms against retrograde aspiration. The American journal of medicine. 1997; 103:64S-73S. [PubMed: 9422627]

5. Mearin F, Ponce J, Ponce M, et al. Frequency and clinical implications of supraesophageal and dyspeptic symptoms in gastroesophageal reflux disease. Eur J Gastroenterol Hepatol. 2012

6. Katz PO. Ambulatory esophageal and hypopharyngeal $\mathrm{pH}$ monitoring in patients with hoarseness. The American journal of gastroenterology. 1990; 85:38-40. [PubMed: 2296961]

7. Koufman JA. The otolaryngologic manifestations of gastroesophageal reflux disease (GERD): a clinical investigation of 225 patients using ambulatory 24-hour $\mathrm{pH}$ monitoring and an experimental investigation of the role of acid and pepsin in the development of laryngeal injury. The Laryngoscope. 1991; 101:1-78. [PubMed: 1895864]

8. Gerhardt DC, Castell DO, Winship DH, et al. Esophageal dysfunction in esophagopharyngeal regurgitation. Gastroenterology. 1980; 78:893-7. [PubMed: 7053042]

9. Torrico S, Kern M, Aslam M, et al. Upper esophageal sphincter function during gastroesophageal reflux events revisited. Am J Physiol Gastrointest Liver Physiol. 2000; 279:G262-7. [PubMed: 10915633]

10. Kahrilas PJ, Dodds WJ, Dent J, et al. Effect of sleep, spontaneous gastroesophageal reflux, and a meal on upper esophageal sphincter pressure in normal human volunteers. Gastroenterology. 1987; 92:466-71. [PubMed: 3792782]

11. Vakil NB, Kahrilas PJ, Dodds WJ, et al. Absence of an upper esophageal sphincter response to acid reflux. Am J Gastroenterol. 1989; 84:606-10. [PubMed: 2729231]

12. Pandolfino JE, Ghosh SK, Zhang Q, et al. Upper sphincter function during transient lower oesophageal sphincter relaxation (tLOSR); it is mainly about microburps. Neurogastroenterology and motility : the official journal of the European Gastrointestinal Motility Society. 2007; 19:20310. [PubMed: 17300290] 
13. Babaei A, Bhargava V, Mittal RK. Upper esophageal sphincter during transient lower esophageal sphincter relaxation: effects of reflux content and posture. Am J Physiol Gastrointest Liver Physiol. 2010; 298:G601-7. [PubMed: 20167874]

14. Lang IM, Medda BK, Shaker R. Mechanisms of reflexes induced by esophageal distension. Am J Physiol Gastrointest Liver Physiol. 2001; 281:G1246-63. [PubMed: 11668034]

15. Paterson WG. Neuromuscular mechanisms of esophageal responses at and proximal to a distending balloon. Am J Physiol. 1991; 260:G148-55. [PubMed: 1987803]

16. Paterson WG, Rattan S, Goyal RK. Esophageal responses to transient and sustained esophageal distension. Am J Physiol. 1988; 255:G587-95. [PubMed: 3189548]

17. Szczesniak MM, Williams RB, Brake HM, et al. Upregulation of the esophago-UES relaxation response: a possible pathophysiological mechanism in suspected reflux laryngitis. Neurogastroenterol Motil. 2010; 22:381-6, e89. [PubMed: 20377793]

18. Torrico S, Corazziari E, Habib FI. Barium studies for detecting esophagopharyngeal reflux events. The American journal of medicine. 2003; 115(Suppl 3A):124S-129S. [PubMed: 12928088]

19. Fouad YM, Katz PO, Hatlebakk JG, et al. Ineffective esophageal motility: the most common motility abnormality in patients with GERD-associated respiratory symptoms. Am J Gastroenterol. 1999; 94:1464-7. [PubMed: 10364008]

20. Vardar R, Sweis R, Anggiansah A, et al. Upper esophageal sphincter and esophageal motility in patients with chronic cough and reflux: assessment by high-resolution manometry. Dis Esophagus. 2013; 26:219-25. [PubMed: 22591118]

21. Siegel CI, Hendrix TR. Esophageal motor abnormalities induced by acid perfusion in patients with heartburn. The Journal of clinical investigation. 1963; 42:686-95. [PubMed: 13992782]

22. Richter JE, Johns DN, Wu WC, et al. Are esophageal motility abnormalities produced during the intraesophageal acid perfusion test? JAMA : the journal of the American Medical Association. 1985; 253:1914-7. [PubMed: 3974081]

23. Burns TW, Venturatos SG. Esophageal motor function and response to acid perfusion in patients with symptomatic reflux esophagitis. Digestive diseases and sciences. 1985; 30:529-35. [PubMed: 3996156]

24. Olsen AM, Schlegel JF. Motility disturbances caused by esophagitis. The Journal of thoracic and cardiovascular surgery. 1965; 50:607-12. [PubMed: 5843967]

25. Kahrilas PJ, Dodds WJ, Hogan WJ, et al. Esophageal peristaltic dysfunction in peptic esophagitis. Gastroenterology. 1986; 91:897-904. [PubMed: 3743966]

26. Schoeman MN, Holloway RH. Integrity and characteristics of secondary oesophageal peristalsis in patients with gastro-oesophageal reflux disease. Gut. 1995; 36:499-504. [PubMed: 7737553]

27. Shaker R, Dodds WJ, Hogan WJ, et al. Mechanisms of Esophagopharygeal Acid Regurgitation. Gastroenterology. 1990; 99:1231.

28. Bardan E, Xie P, Aslam M, et al. Disruption of primary and secondary esophageal peristalsis by afferent stimulation. American journal of physiology. Gastrointestinal and liver physiology. 2000; 279:G255-61. [PubMed: 10915632]

29. Pandolfino JE, Shi G, Zhang Q, et al. Absence of a deglutitive inhibition equivalent with secondary peristalsis. American journal of physiology. Gastrointestinal and liver physiology. 2005; 288:G671-6. [PubMed: 15604200] 

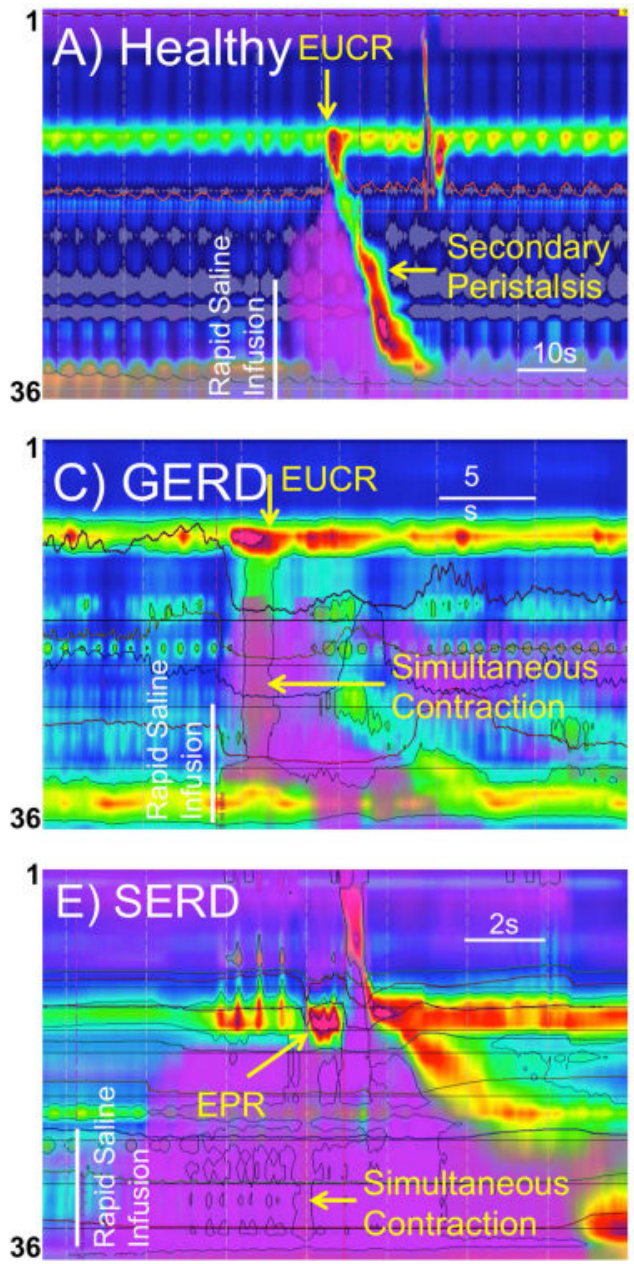
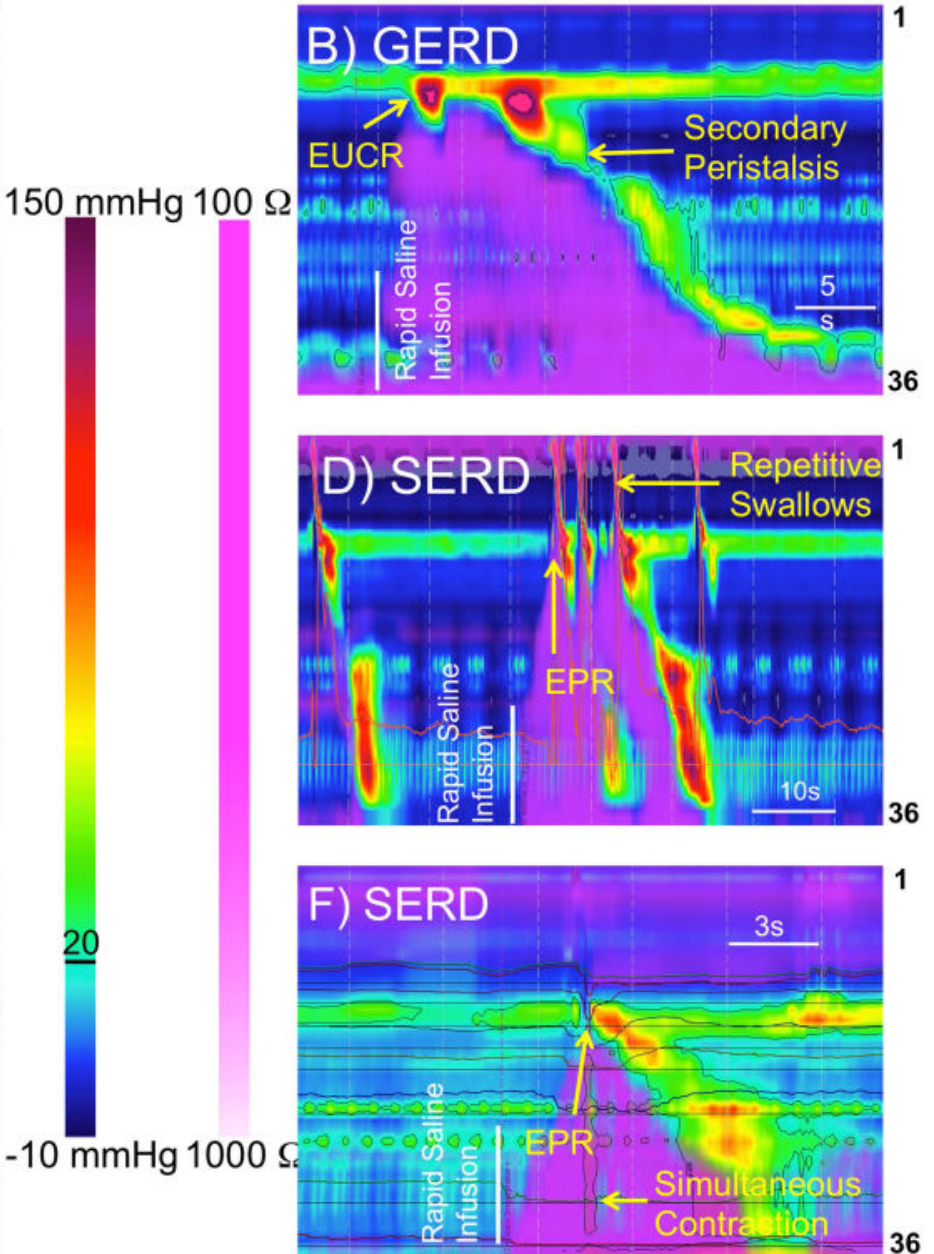

Figure-1. Distal esophageal rapid saline infusion elicits different responses in healthy controls (A), GERD (B-C) and SERD (D-F) patients

A and B) Extension of infusate into the cervical esophagus is followed by strong esophagoUES contractile reflex (EUCR), and a secondary peristaltic wave transporting the infusate away from UES into the stomach. C) Rapid distal esophageal saline injection is followed by esophago-UES contractile reflex (EUCR), and a simultaneous esophageal contraction without esophageal clearance. D) Extension of the infusate into the cervical esophagus of a SERD patient elicits transient UES relaxation and results in immediate esophagopharyngeal reflux (EPR), and repetitive defensive swallows to clear hypopharynx from the infusate. E and F) shortly after saline injection, saline reaches the lower border of UES in SERD patients. Non-peristaltic esophageal contraction coupled with a transient incomplete UES relaxation results in EPR evidenced by retrograde hypopharyngeal impedance drop. 


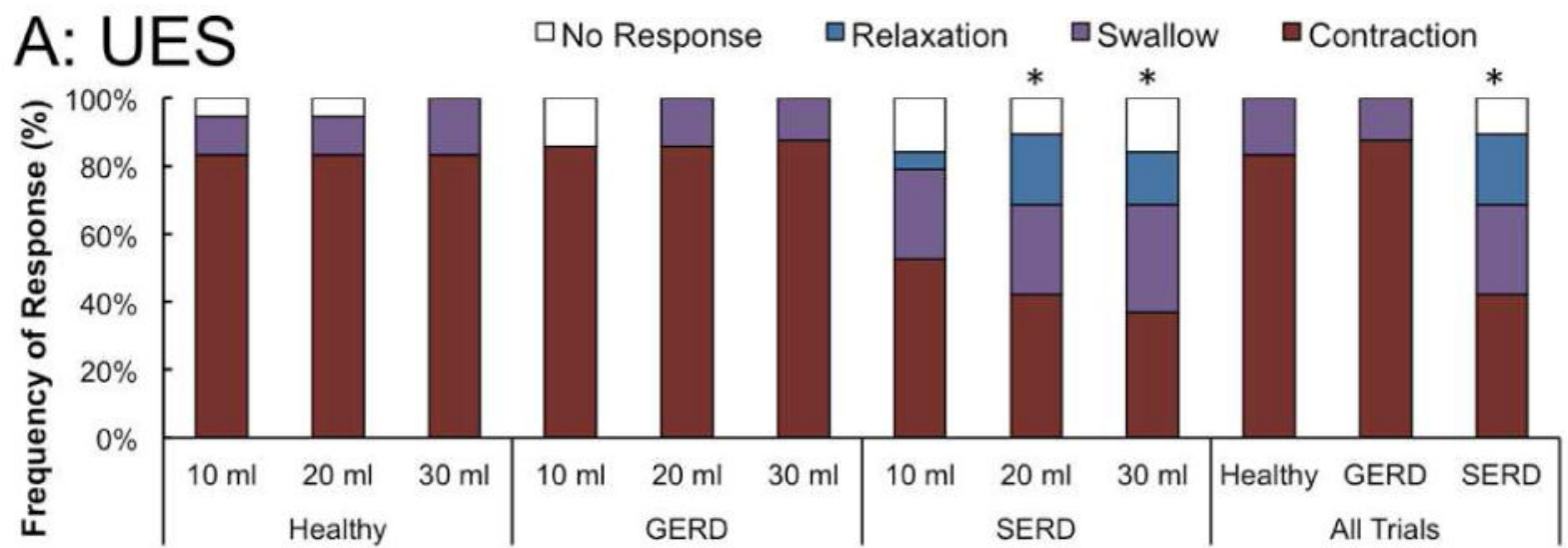

\section{B: EsophaguS $\square$ No Response $\square$ Non-peristaltic Contraction $\square$ Peristaltic Contraction}
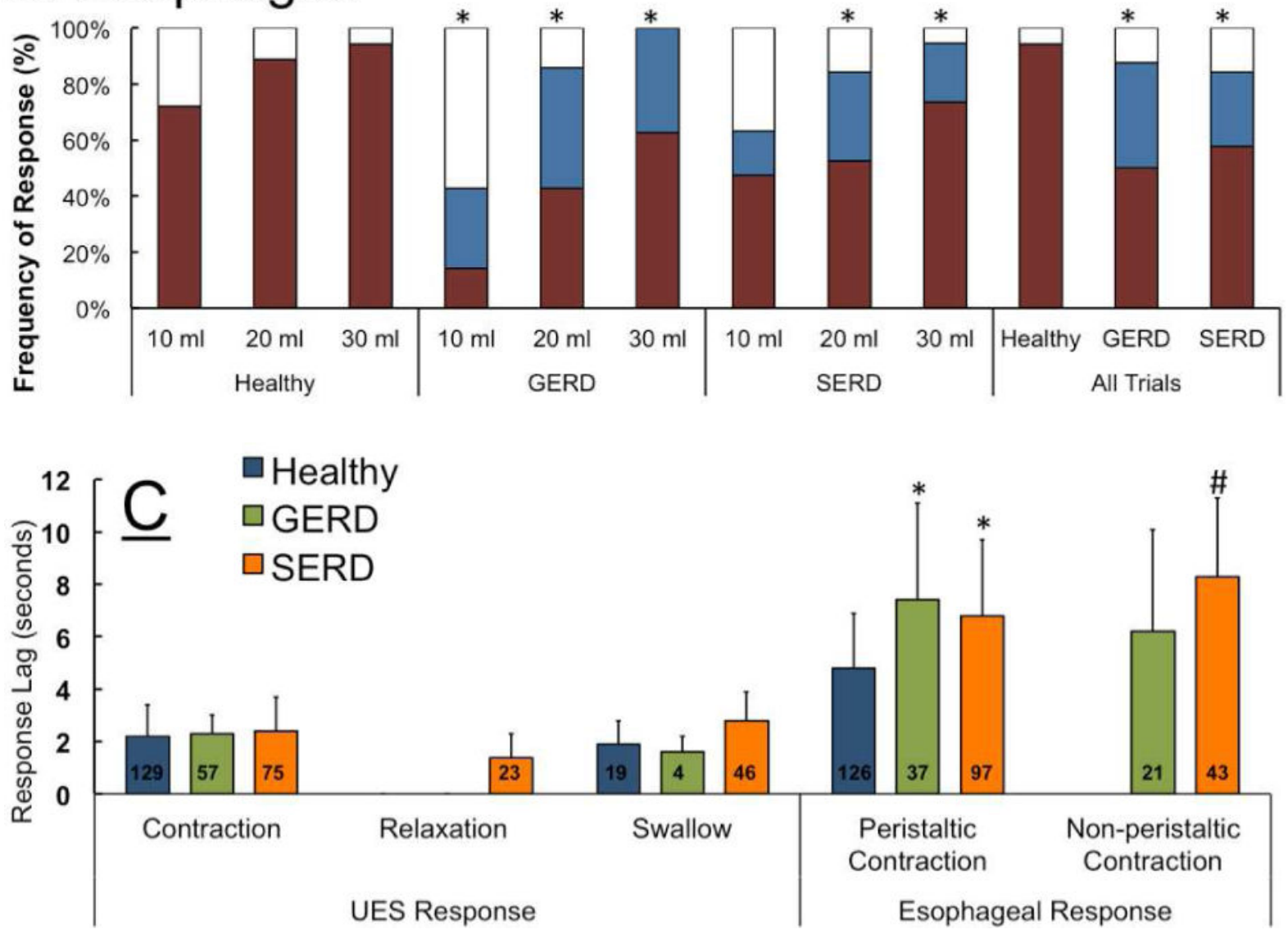


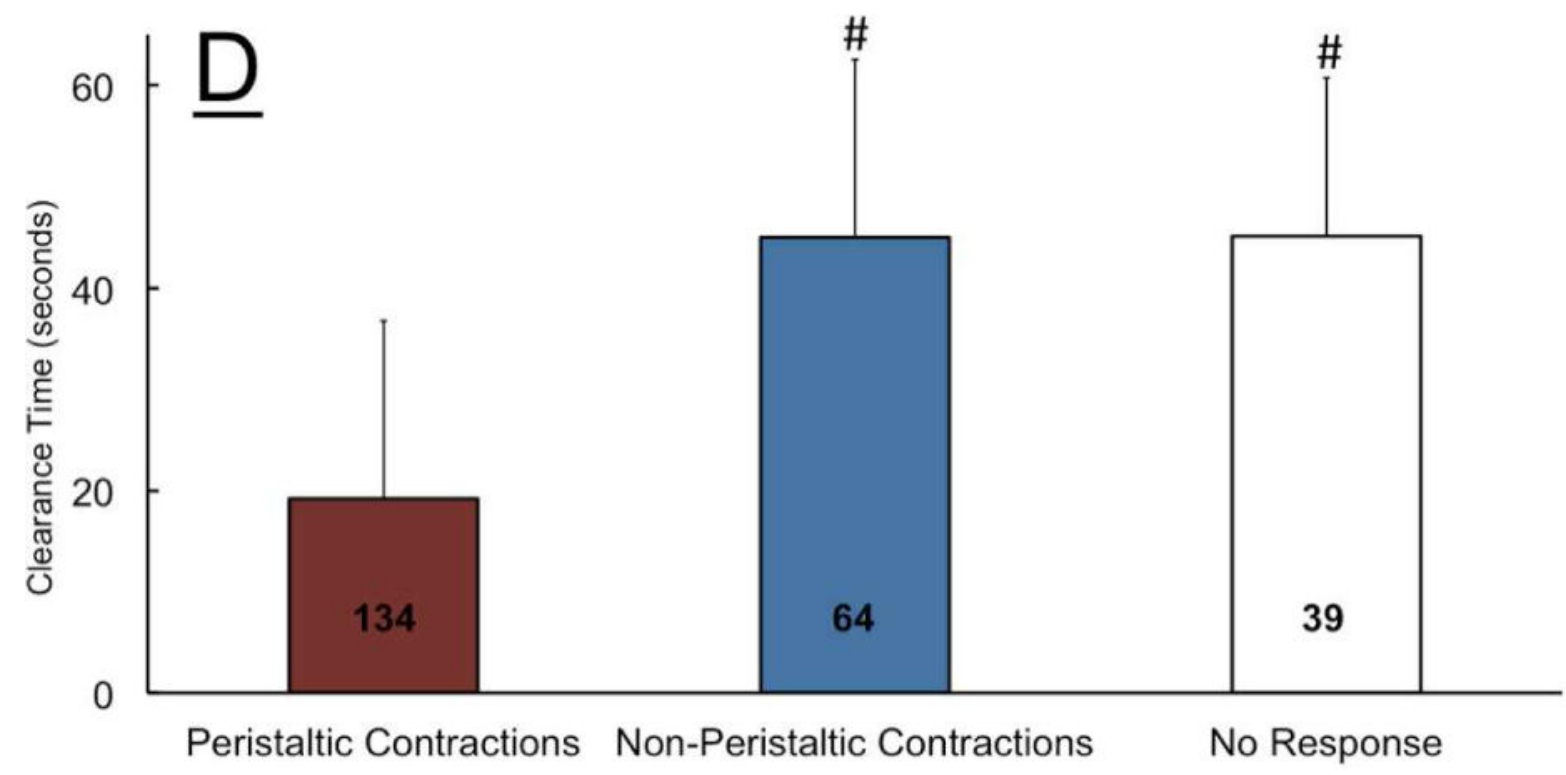

Figure-2. Frequency of elicitation and temporal characteristics of UES and esophageal contractile response, along with esophageal clearance after distal esophageal rapid saline injection in healthy controls $(n=18)$, GERD $(n=8)$ and SERD $(n=19)$ subjects

A) Esophago-UES contractile reflex (EUCR) was the predominant response in majority of healthy controls and GERD patients. SERD subjects exhibited a transient UES relaxation response that was never observed in healthy controls and GERD patients. SERD patients also showed significantly less EUCR compared to healthy controls ( $* p<0.05$ ). B) Bolus saline injection in overwhelming majority of healthy controls was cleared by a peristaltic wave (secondary or primary). GERD and SERD patients though often demonstrated nonperistaltic contractions while healthy controls showed them rarely ( $* p<0.05)$. C) Time lag from onset of esophageal rapid saline injection to elicitation of EUCR, transient relaxation and initial esophageal contractile response. Esophageal contractile response occurred later than UES response, and was significantly delayed in GERD and SERD subjects compared to healthy controls (* $p<0.05$ and $\left.{ }^{*} p<0.01\right)$. D) Quantitative analysis of esophageal stasis following saline infusion in GERD and SERD patients ( $\mathrm{N}=27)$. Non-peristaltic esophageal contractions and lack of early esophageal contractile activity are similarly associated with delayed luminal clearance and resultant esophageal stasis. (\# $p<0.01, n=$ number of infusion trials demonstrating response in each group). 

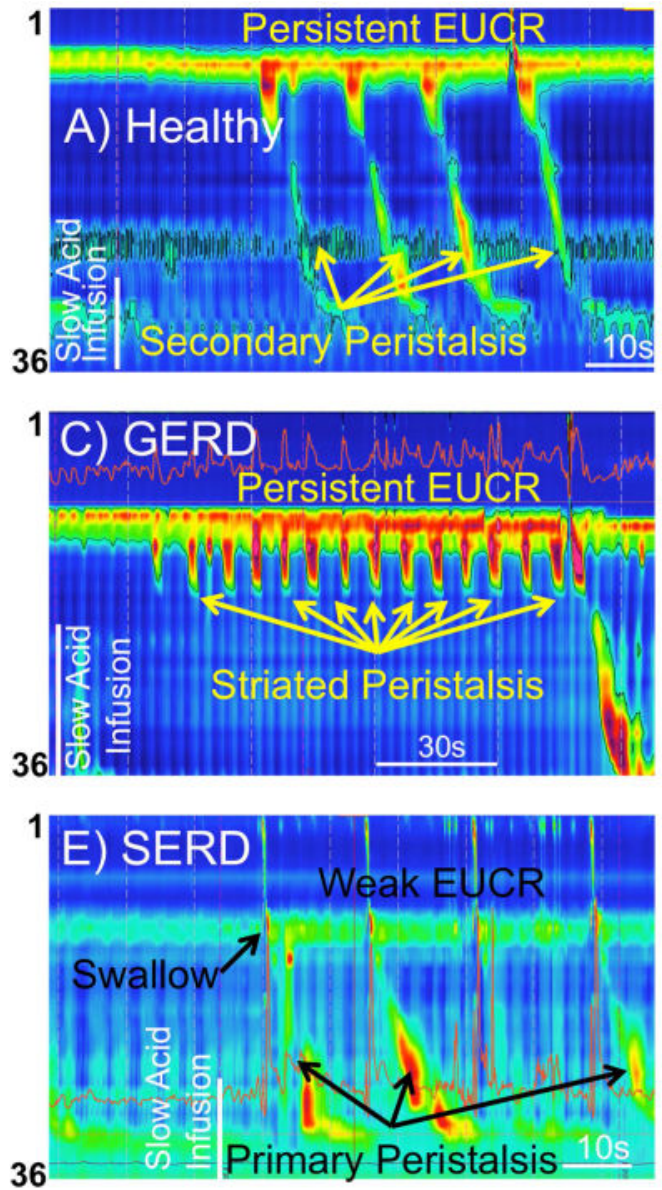
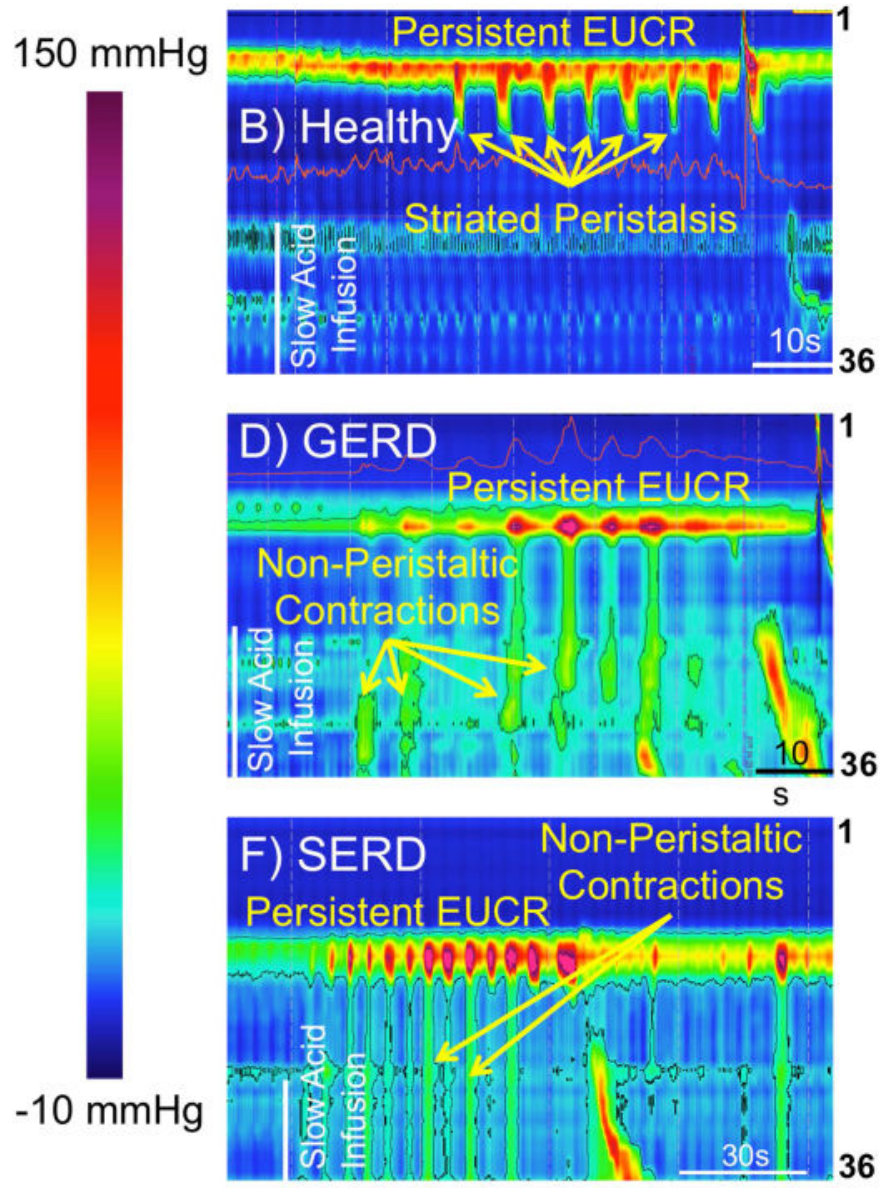

Figure-3. Slow esophageal acid infusion elicits distinctive response in healthy controls (A-B), GERD (C-D) and SERD (E-F) patients

Healthy controls show persistent esophago-UES contractile response (EUCR) associated with repetitive peristaltic waves (A). A unique pattern of persistent EUCR associated with peristaltic waves limited to the striated-muscle segment of esophagus while distal smoothmuscle esophagus is inhibited was observed in healthy control (B) and GERD patients (C). Slow acid infusion is often followed by rhythmic UES contractions (robust EUCR) accompanied by repetitive non-peristaltic esophageal contractions in GERD (D) and SERD (F) patients. E) Repetitive swallows associated primary peristalsis follow slow acid infusion in a SERD patient. Impaired EUCR and brief episodes of UES relaxation are observed before and after the third swallow. 
A $\begin{aligned} & \square \text { No Response } \\ & \text { a Swallow } \\ & \text { aUES Contraction }\end{aligned}$

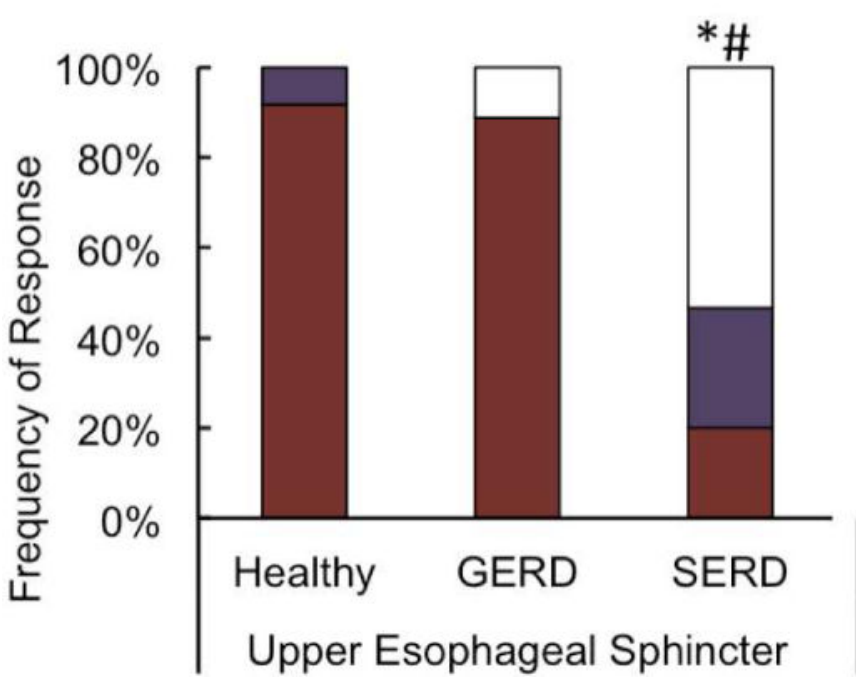

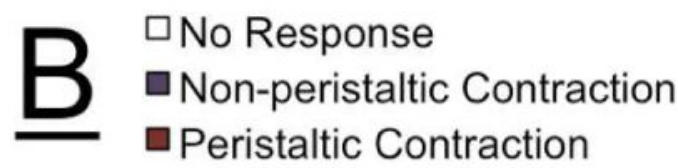

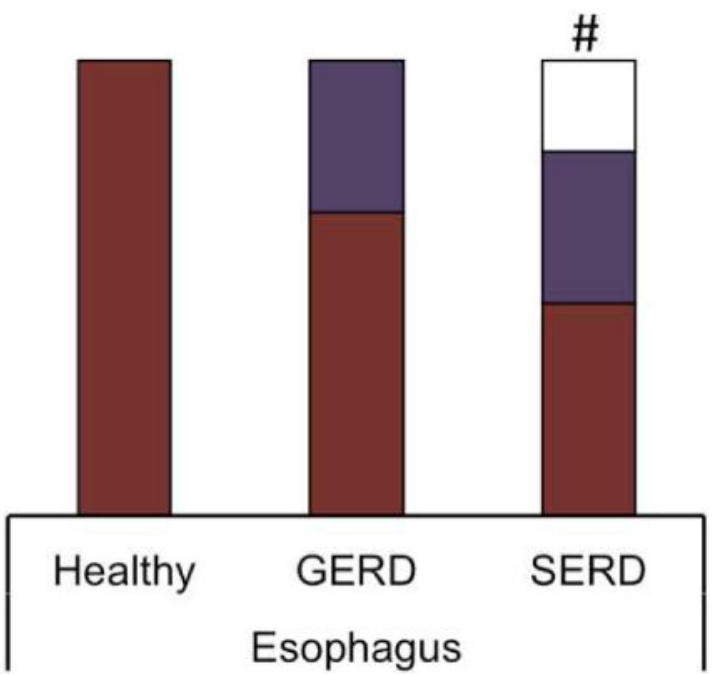

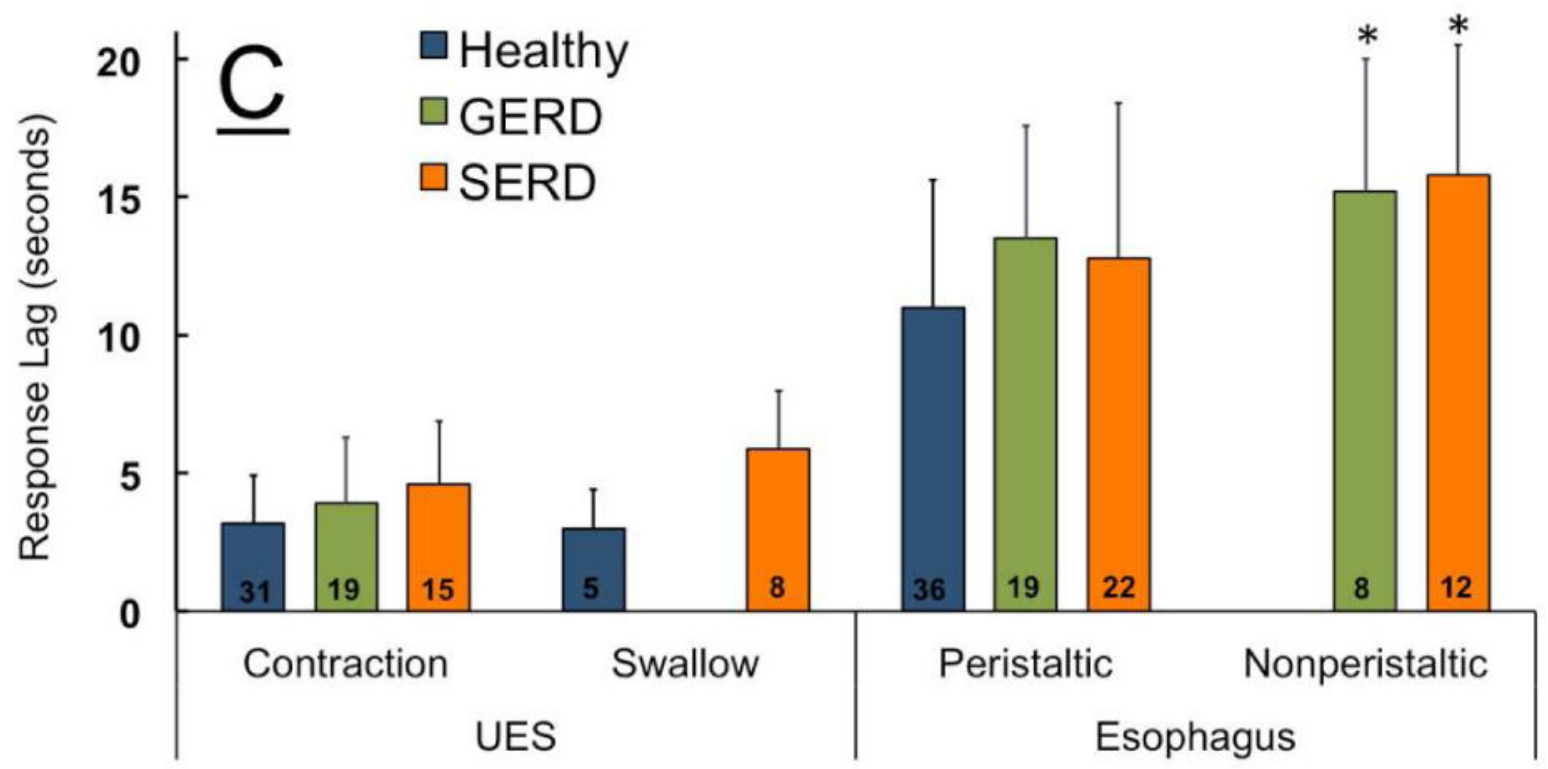

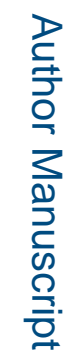



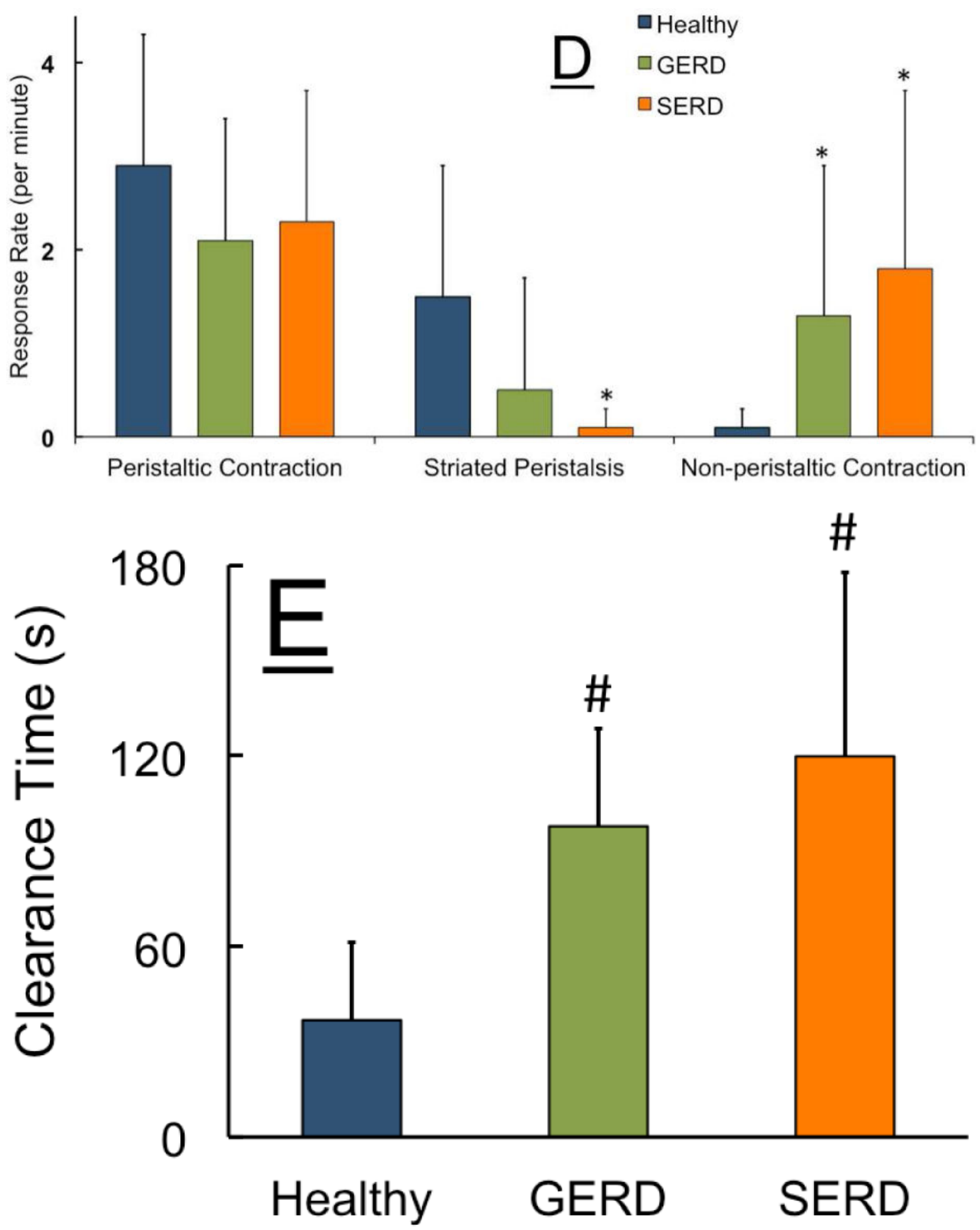

Figure-4. Frequency of elicitation, rate and temporal characteristics of UES and esophageal contractile response during slow esophageal acid infusion in healthy controls $(n=12)$, GERD $(n=9)$ and SERD $(n=15)$ patients

A) Overwhelming majority of healthy controls and GERD patients showed esophago-UES contractile response (EUCR). In contrast, SERD patients frequently demonstrated no 
discernable UES response $\left(* p<0.01\right.$ and ${ }^{*} p<0.001$ compared to GERD and healthy respectively). While healthy controls universally responded by esophageal peristaltic contraction following slow acid infusion, GERD and SERD patients often exhibited nonperistaltic esophageal contractions ( ${ }^{\#} p<0.001$ compared to healthy). C) Non-peristaltic esophageal contractions in GERD and SERD patients were significantly delayed compared to peristaltic contraction counterparts in healthy controls $\left(^{*} p<0.05, n=\right.$ number of infusion trials demonstrating response in each group). D) Rate of esophageal contractile activity during total 180 seconds of ongoing acid infusion over three trials was measured. Striated peristaltic waves were predominantly seen in healthy controls, while in contrast esophageal non-peristaltic contractions were significantly more common in GERD and SERD patients $(* p<0.05)$. E) Duration from termination of acid infusion till complete esophageal clearance from infusate was measured up to 180 seconds. Both GERD and SERD patients showed longer duration of esophageal stasis compared to healthy controls $\left({ }^{\#} p<0.001\right.$, $n=$ number of infusion trials demonstrating response in each group). 

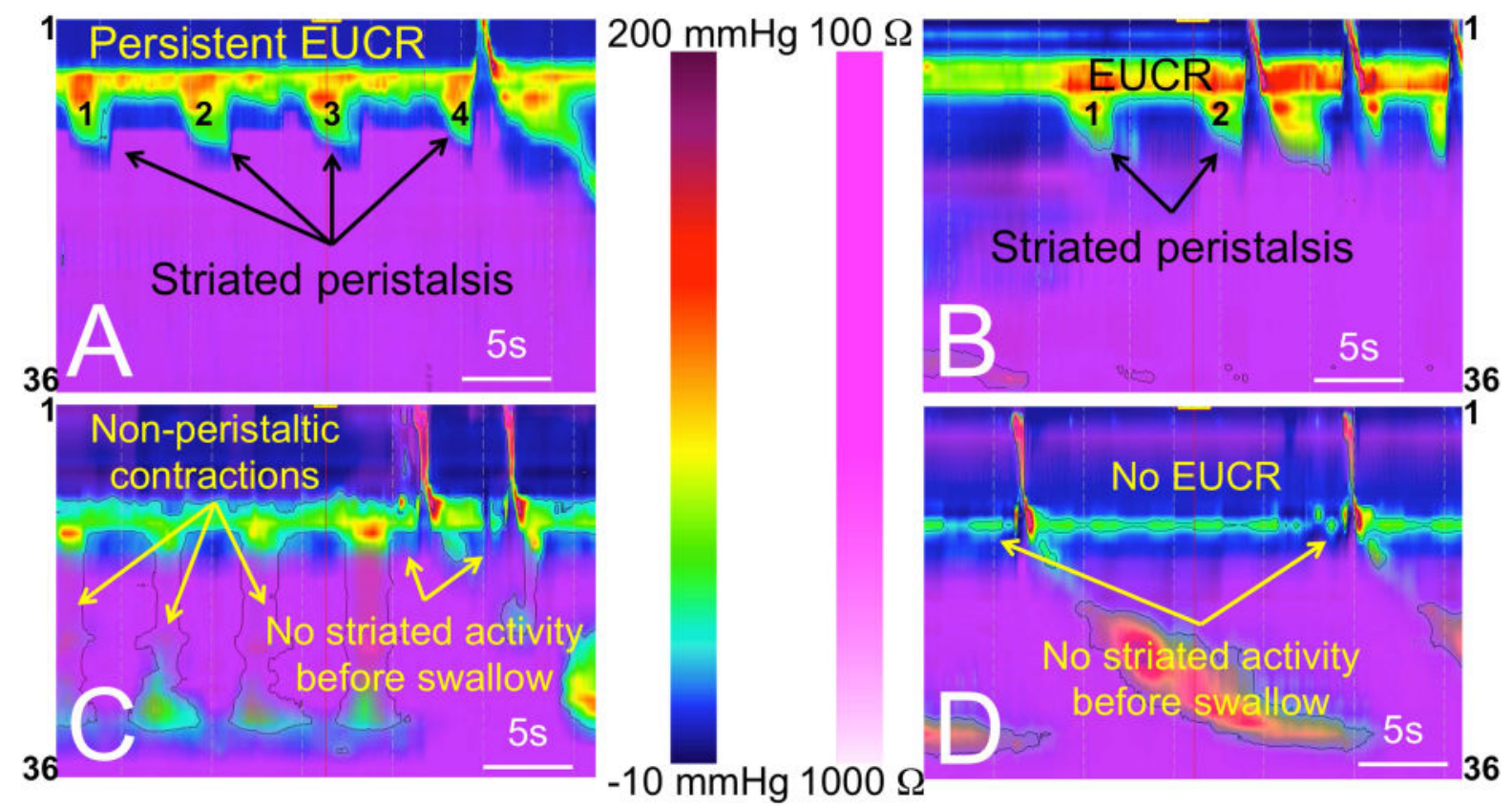

Figure-5. Healthy controls distinctively demonstrate a unique pattern of striated-muscle peristaltic waves while distal smooth-muscle esophagus is quiescent

A-B) In healthy controls, when the infusate reaches proximal esophagus a robust esophagoUES contractile reflex (EUCR), and sometimes a unique pattern of striated peristaltic waves sweep the infusate away from UES. Perhaps more importantly, when infusate is in close proximity of the lower border of UES, striated-muscle activity is universally present prior to any swallow-related UES relaxation. C-D) SERD patients frequently show impaired EUCR and non-peristaltic esophageal contractions. They frequently do not mount any esophageal striated activity prior to swallow-related UES relaxation despite exposure of the lower border of UES to infusate. 

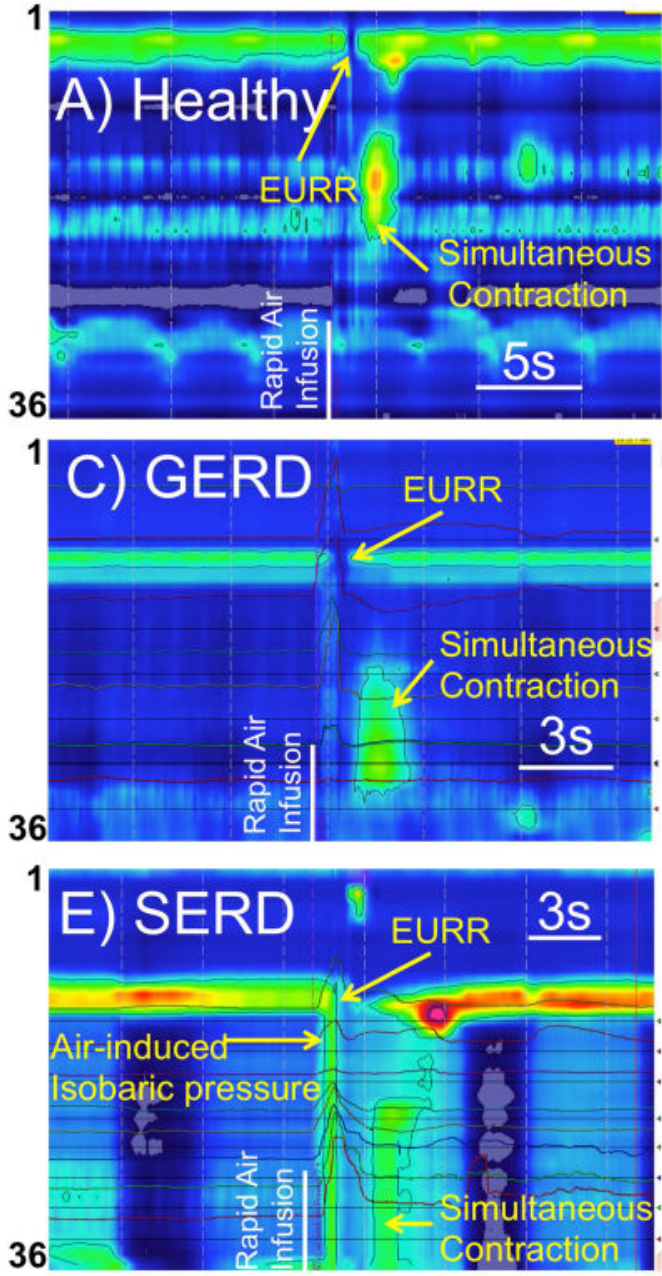
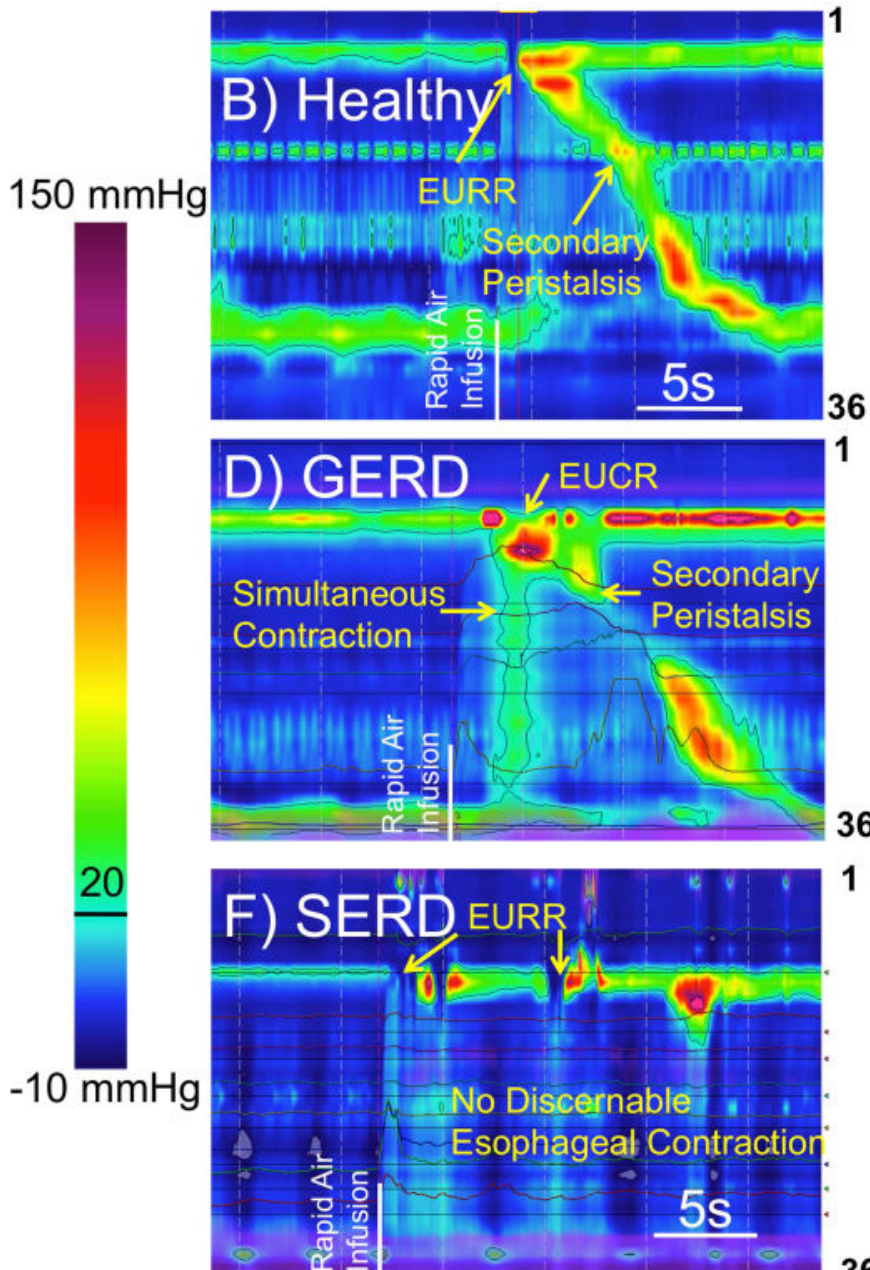

Figure-6. Distal esophageal rapid air injection elicits predominantly esophago-UES relaxation reflex (EURR) in healthy controls (A-B), GERD (C-D) and SERD (E-F) patients Distal esophageal simultaneous contraction was observed shortly after onset of UES relaxation $(\mathrm{A}, \mathrm{C}, \mathrm{D}, \mathrm{E})$ in all groups. Occasionally a secondary peristaltic wave was triggered in healthy controls and GERD patients $(\mathrm{B}, \mathrm{D})$ or no discernable esophageal contractile activity could be recognized after air injection (F). The reported air-induced simultaneous contraction as shown was distinctly after termination of air infusion and not consistent with esophageal isobaric pressurization (E). 
A: UES $\quad$ No Response $\quad$ Contraction घRelaxation
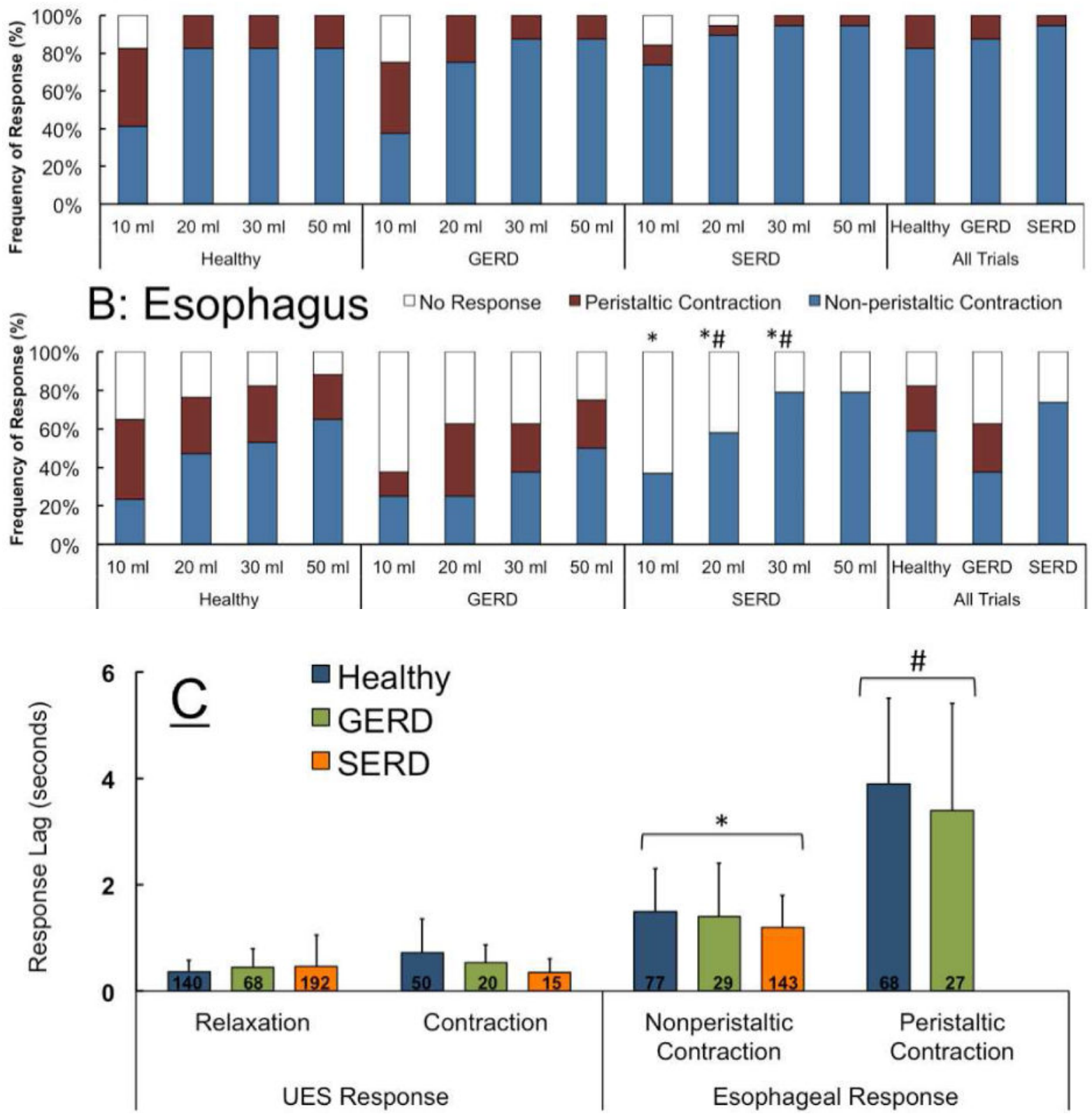

Figure-7. Frequency of elicitation and temporal characteristics of UES and esophageal response to distal esophageal rapid air injection $(10,20,30$ and $50 \mathrm{ml})$ in healthy controls $(\mathrm{n}=18)$, GERD $(n=8)$ and SERD $(n=19)$ subjects

A) Esophago-UES relaxation reflex (EURR) was the predominant response in majority of participants. B) Initial esophageal contractile response to bolus air injection was either a non-peristaltic distal esophageal contraction, or a peristaltic response during analysis window. SERD patients never showed peristaltic response to air injection (*compared to healthy and " compared to GERD, $p<0.05)$. C) Time lag from onset of esophageal rapid air injection to elicitation of EURR, esophago-UES contractile reflex (EUCR) and esophageal contractile response. Esophageal contractile response occurred universally later than onset of 
UES response. Peristaltic contraction was significantly delayed compared to non-peristaltic contractions $\left({ }^{*} p<0.05\right.$ and ${ }^{\#} p<0.01$ compared to UES response and non-peristaltic contraction, $n=$ number of infusion trials demonstrating response in each group). 